\title{
Cosmic rays and space weather: effects on global climate change
}

\author{
L. I. Dorman \\ Israel Cosmic Ray \& Space Weather Center and Emilio Segre' Observatory, Tel Aviv University, \\ Technion and Israel Space Agency, Israel
}

Cosmic Ray Department of IZMIRAN, Russian Academy of Science, Russia

Correspondence to: L. I. Dorman (lid@ physics.technion.ac.il)

Received: 1 February 2011 - Revised: 12 September 2011 - Accepted: 9 October 2011 - Published: 4 January 2012

\begin{abstract}
We consider possible effects of cosmic rays and some other space factors on the Earth's climate change. It is well known that the system of internal and external factors formatting the climate is very unstable; decreasing planetary temperature leads to an increase of snow surface, and decrease of the total solar energy input into the system decreases the planetary temperature even more, etc. From this it follows that even energetically small factors may have a big influence on climate change. In our opinion, the most important of these factors are cosmic rays and cosmic dust through their influence on clouds, and thus, on climate.
\end{abstract}

Keywords. History of geophysics (Atmospheric sciences; Solar-planetary relationships) - Interplanetary physics (Cosmic rays)

\section{Introduction}

It is now obvious, according to past data on large variations in planetary surface temperature over timescales of many thousands (even millions) of years, that the Earth's global climate change is determined not only by internal factors but also by factors originating in space. These include the moving of the solar system around the center of our galaxy, thus crossing galactic arms, clouds of molecular dust, nearby supernovae and supernova remnants. Another important space factor is the cyclic variations of solar activity and the solar wind (mostly on the scales of decades and hundreds of years). The space factors which influence Earth's climate most, however, are cosmic rays (CR) and space dust, which influence the formation of clouds and therefore control the total energy transferred from the Sun to the Earth's atmosphere. The propagation and modulation of galactic CR (generated mostly during supernova explosions and in supernova remnants in our galaxy) is determined within the heliosphere by their interaction with magnetic fields frozen in the solar wind and in coronal mass ejections (CME) with accompanying interplanetary shock waves (that produce big magnetic storms during their interactions with the Earth's magnetosphere). The most difficult problem of monitoring and forecasting the modulation of galactic $\mathrm{CR}$ in the heliosphere is that the CR intensity at some 4-D point in space-time is determined not only by the level of solar activity at the time of the observations or the electromagnetic conditions at this point, but rather, by the electromagnetic conditions in the total Heliosphere. These conditions in the total heliosphere are determined by the development of solar activity during many months leading up to the time-point of observations. This is the cause of the so-called hysteresis phenomenon in connecting galactic CR and solar activity. On the other hand, detailed investigations of this phenomenon yield the important possibility to estimate conditions in and the dimensions of the heliosphere. To solve the problem described above of CR modulation in the heliosphere, we considered as the first step the behavior of high energy particles (more than several $\mathrm{GeV}$, for which the diffusion time of propagation in the heliosphere is very small in comparison with the characteristic time of modulation) on the basis of neutron monitor data in the frame of convection diffusion theory. We then take into account drift effects. For low energy galactic CR detected on satellites and space probes, we also need to take into account the additional time lag caused by diffusion in the heliosphere. Then, we consider the problem of CR modulation forecasting for several months and years ahead, which gives the possibility to forecast some part of the global climate change caused by CR. 


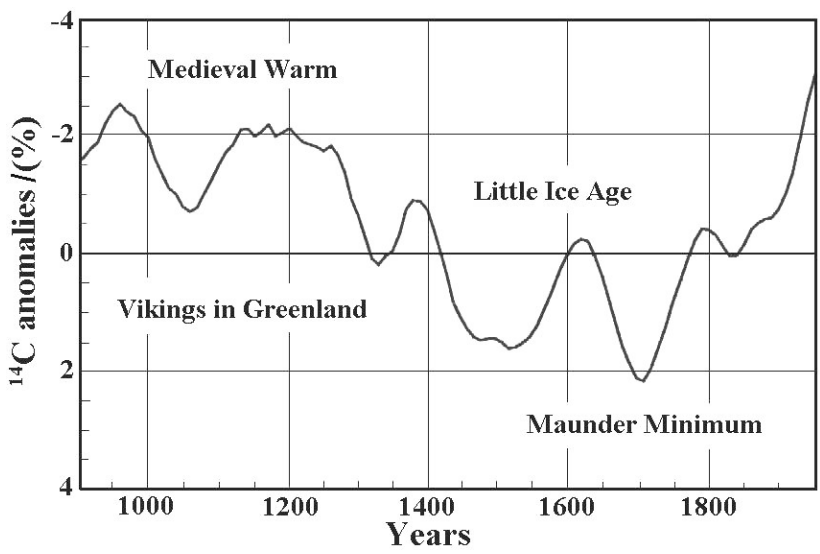

Fig. 1. The change of CR intensity reflected in radiocarbon concentration during the last millennium. The Maunder minimum refers to the period 1645-1715, when number of sunspots was very small. According to Svensmark (2000).

\section{Solar activity and CR variations as possible causes of climate change}

About two hundred years ago, the famous astronomer William Herschel (1801) suggested that the price of wheat in England was directly related to the number of sunspots with periodicity about $11 \mathrm{yr}$. He noticed that less rain fell when the number of sunspots was big (Joseph in the Bible, recognised a similar periodicity in food production in Egypt, about $4000 \mathrm{yr}$ ago). The solar activity level is known from direct observations over the past $450 \mathrm{yr}$ and from data of cosmogenic nuclides (through CR intensity variations) for more than $10000 \mathrm{yr}$ (see details in Chapters 10 and 17 in Dorman, 2004). Over this period there is a striking qualitative correlation between cold and warm climate periods and high and low levels of galactic CR intensity, correspondingly (low and high solar activity). As an example, Fig. 1 shows the change in the concentration of radiocarbon ${ }^{14} \mathrm{C}$ during the last millennium (a higher concentration of radiocarbon corresponds to a higher intensity of galactic CR and to lower solar activity). It can be seen from Fig. 1 that during 1000-1300 the CR intensity was low and solar activity high, which coincided with the warm medieval period (during this period Vikings settled in Greenland). After 1300 solar activity decreased and CR intensity increased, and a long cold period followed (the so called Little Ice Age, which included the Maunder minimum 1645-1715 and lasted until the middle of 19th century).

\section{The possible role of solar activity and solar irradiance in climate change}

Friis-Christensen and Lassen (1991), Lassen and FriisChristensen (1995) found, from four hundred years of data, that the filtered solar activity cycle length is closely connected to variations of the average surface temperature in the Northern Hemisphere. Labitzke and Van Loon (1993) showed, from solar cycle data, that the air temperature increases with increasing levels of solar activity. Svensmark (2000) and Shapiro et al. (2011) also discussed the problem of the possible influence of solar activity on the Earth's climate through changes in solar irradiance. But the direct satellite measurements of the solar irradiance during the last two solar cycles showed that the variations during a solar cycle was only about $0.1 \%$, corresponding to about $0.3 \mathrm{~W} \mathrm{~m}^{-2}$. This value is too small to explain the observed climate changes during solar cycles (Lean et al., 1995). The reconstruction of solar irradiance from $7000 \mathrm{BC}$ up to $500 \mathrm{AD}$ shows variations from 1358 up to $1370 \mathrm{~W} \mathrm{~m}^{-2}$, i.e. not more than $1 \%$ (Shapiro et al., 2011). Much bigger changes during a solar cycle occur in UV radiation: according to Shapiro et al. (2011), the flux of solar irradiation during $1600-2000$ in interval $500-600 \mathrm{~nm}$ varied in limits of $0.4 \%$, in $370-400 \mathrm{~nm}$ (CN violet system) $-3.2 \%$, in 200-242 nm (Herzberg continuum) $-10.9 \%$, and in 175$200 \mathrm{~nm}$ (Schumann-Runge bands) $-26.6 \%$ (these changes are important for variations in formation of the ozone layer). Haigh (1996), and Shindell et al. (1999) suggested that the heating of the stratosphere by UV radiation can be dynamically transported into the troposphere. This effect might be responsible for small contributions towards 11 and $22 \mathrm{yr}$ cycle modulation of climate but not to the $100 \mathrm{yr}$ or more of climate changes that were observed in the past and during the last hundred years (Dobrica et al., 2009). Hong et al. (2011) examined the effect of the 11-yr solar cycle and quasi-biennial oscillation on the 27-day solar rotational period detected in tropical convective cloud activity (it was analyzed data of outgoing long wave radiation for 1979-2004).

\section{Cosmic rays as an important link between solar activity and climate change}

Many authors have considered the influence of galactic and solar CR on the Earth's climate. Cosmic radiation is the main source of air ionization below 40-35 km (only near the ground level, lower than $1 \mathrm{~km}$, are radioactive gases from the soil also important in air ionization - see review in Dorman, 2004). The first who suggest a possible influence of air ionization by CR on the climate was Ney (1959). Svensmark (2000) noted that the variation in air ionization caused by CR could potentially influence the optical transparency of the atmosphere, by either a change in aerosol formation or influence the transition between the different phases of water. Many authors considered these possibilities (Dickinson, 1975; Pudovkin and Raspopov, 1992; Pudovkin and Veretenenko, 1995, 1996; Belov et al., 2005; Dorman, 2005a, b, 2006, 2007). The possible statistical connections between the solar activity cycle and the corresponding long term CR 
Table 1. Global annual mean forcing due to various types of clouds, from the Earth Radiation Budget Experiment (ERBE), according to Hartmann (1993). The positive forcing increases the net radiation budget of the Earth and leads to a warming; negative forcing decreases the net radiation and causes a cooling. (Note that the global fraction implies that $36.7 \%$ of the Earth is cloud free.)

\begin{tabular}{lrrrrrrrrr}
\hline Parameter & \multicolumn{2}{c}{ High clouds } & & \multicolumn{2}{c}{ Middle clouds } & & Low clouds & Total \\
\cline { 2 - 3 } & Thin & Thick & & Thin & Thick & & All & \\
\hline Global fraction/(\%) & 10.1 & 8.6 & & 10.7 & 7.3 & & 26.6 & 63.3 \\
\hline Forcing (relative to clear sky): & & & & & & & & \\
\hline Albedo (SW radiation) $/\left(\mathrm{Wm}^{-2}\right)$ & -4.1 & -15.6 & & -3.7 & -9.9 & & -20.2 & -53.5 \\
Outgoing $(\mathrm{LW} \mathrm{radiation}) /\left(\mathrm{Wm}^{-2}\right)$ & 6.5 & 8.6 & & 4.8 & 2.4 & & 3.5 & 25.8 \\
(Net forcing $/\left(\mathrm{Wm}^{-2}\right)$ & 2.4 & -7.0 & & 1.1 & -7.5 & & -16.7 & -27.7 \\
\hline
\end{tabular}

intensity variations with characteristics of climate change were considered in Dorman et al. (1987, 1988a, b). Dorman et al. (1997) reconstructed CR intensity variations over the last four hundred years on the basis of solar activity data, and compared the results with radiocarbon data.

Cosmic rays play a key role in the formation of thunderstorms and lightnings (see extended review in Dorman, 2004, Chapter 11). Many authors (Markson, 1978; Price, 2000; Tinsley, 2000; Schlegel et al., 2001; Dorman and Dorman, 2005; Dorman et al., 2003) have considered atmospheric electric field phenomena as a possible link between solar activity and the Earth's climate. Barnard et al. (2011) used data on cosmogenic nucleus in ice for about $9300 \mathrm{yr}$ for investigation of great solar energetic particle events and long-time galactic cosmic ray variations for research of space climate in the past and possible predictions for some time ahead. The obtained important information can be used for investigation of the link between cosmic ray intensity and the Earth's climate change. Also important in the relationship between CR and climate, is the influence of long term changes in the geomagnetic field on CR intensity through the changes of cutoff rigidity (see review in Dorman, 2009). It can be considering the general hierarchical relationship: (solar activity cycles + long-term changes in the geomagnetic field) $\rightarrow$ (CR long term modulation in the Heliosphere + long term variation of cutoff rigidity) $\rightarrow$ (long term variation of clouds covering and aerosols + atmospheric electric field effects) $\rightarrow$ climate change.

\section{The connection between galactic CR solar cycles and the Earth's cloud coverage}

Recent research has shown that the Earth's cloud coverage (observed by satellites) is strongly influenced by CR intensity (Svensmark, 2000; Marsh and Svensmark, 2000a, b). Clouds influence the irradiative properties of the atmosphere by both cooling through reflection of incoming short wave solar radiation, and heating through trapping of outgoing long wave radiation (the greenhouse effect). The overall re-

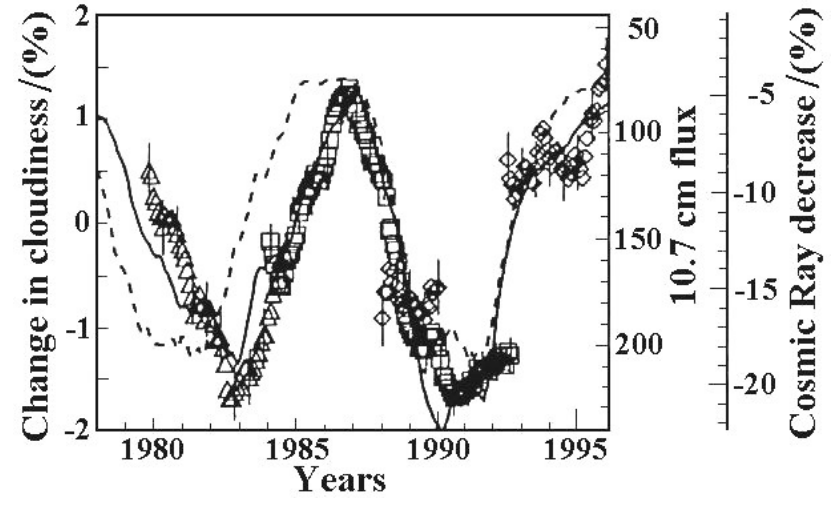

Fig. 2. Changes in the Earth's cloud coverage: triangles - from satellite Nimbus 7); squares - from the International Satellite Cloud Climatology Project); diamonds - from the Defense Meteoroloical Satellite Program). Solid curve - CR intensity variation according to Climax neutron monitor, normalized to May 1965. Broken curve - solar radio flux at $10.7 \mathrm{~cm}$. All data are smoothed using twelve months running mean. According to Svensmark (2000).

sult depends largely on the height of the clouds. According to Hartmann (1993), high optically thin clouds tend to heat while low optically thick clouds tend to cool (see Table 1). According to Smith at al. (2011), the Clouds and Earth Radiant Energy System (CERES) project's objectives are to measure the reflected solar radiance (shortwave) and Earthemitted (longwave) radiances and from these measurements to compute the shortwave and longwave radiation fluxes at the top of the atmosphere and the surface and radiation divergence within the atmosphere. Connection of CR intensity global variation with the Earth cloud covering is illustrated by Fig. 2, and separately with different types of clouds - by Fig. 3.

From Fig. 2 it can be seen that variation in cloudiness corresponds very well to variation in CR without any time lag, and the decreasing of CR intensity in Climax neutron monitor on $15 \%$ corresponds decreasing in cloudiness on about $3 \%$ (positive correlation). From other hand, from Table 1 we 


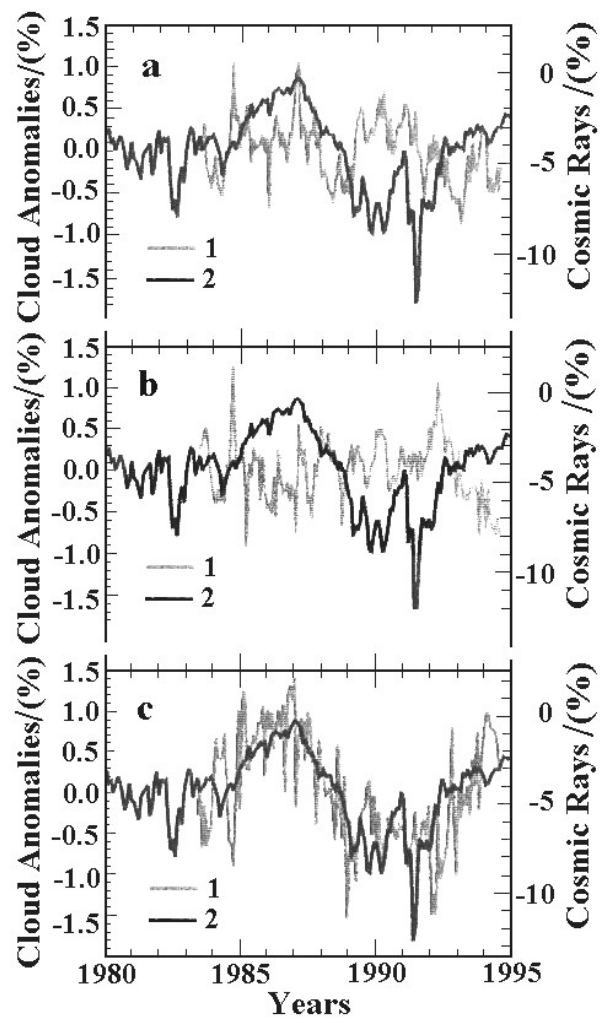

Fig. 3. CR intensity obtained at the Huancayo/Haleakala neutron monitor (normalized to October 1965, curve 2) in comparison with global average monthly cloud coverage anomalies (curves 1) at heights, $H$, for: (a) - high clouds, $H>6.5 \mathrm{~km}$, (b) - middle clouds, $6.5 \mathrm{~km}>H>3.2 \mathrm{~km}$, and (c) - low clouds, $H<3.2 \mathrm{~km}$. According to Marsh and Svensmark (2000).

can see that the total cloudiness gives input of solar energy $27.7 \mathrm{~W} \mathrm{~m}^{-2}$, so $3 \%$ decreasing of cloudiness will give about $+1 \mathrm{~W} \mathrm{~m}^{-2}$.

From Fig. 3 it can be seen that practically is no connection between CR intensity variations and changes in cloudiness for high and middle altitude clouds (panels a and b), but is a high positive correlation for low altitude clouds (panel c).

\section{On connection of $C R$ variation with surface planetary temperature during the last thousand years and during 1935-1995}

From Sect. 4 it follows that with CR intensity decreasing, planetary cloudiness decreases leading to increase of solar energy input in the low atmosphere and increase of planetary surface temperature. This can be demonstrated by data of radiocarbon for the last thousand years (see Fig. 1) and by direct CR measurements for about $60 \mathrm{yr}$ from 1935 to 1995 (see Fig. 4)

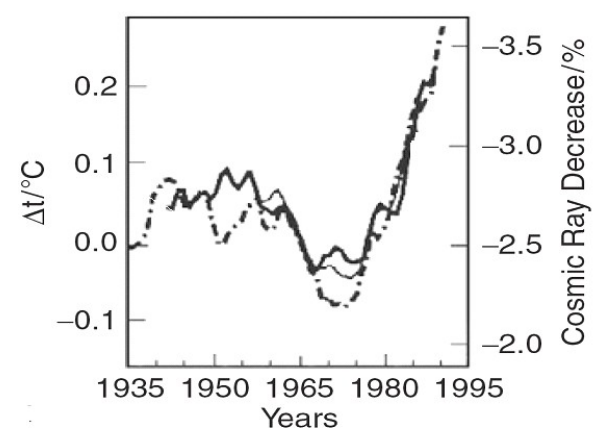

Fig. 4. Eleven year average Northern Hemisphere marine and land air temperature variation $\Delta t$ (broken curve), compared with eleven year average CR intensity: thick solid curve - from data of Compton type ionization chambers shielded by $10 \mathrm{~cm} \mathrm{~Pb}$ (1937-1994, normalized to 1965), and thin solid curve - from Climax neutron monitor (normalized to ion chambers, 1953-1994). According to Svensmark (2000).

\section{Solar irradiance and cosmic ray fluxes during Maunder minimum: influence on climate change}

During the Maunder minimum the CR intensity was very high, so the planetary surface temperature is expected to be lower than in years with high level of solar activity. As was shown above (see Fig. 1), exactly this was observed by using ${ }^{14} \mathrm{C}$ data. More detail data on solar irradiation flux, CR intensity (through ${ }^{10} \mathrm{Be}$ ), and the air surface temperature are shown in Fig. 5. From Fig. 5 can be clear seen that non solar irradiance, but CR intensity variation is mostly responsible for observed climate change during Maunder minimum.

\section{Variations of CR Intensity and wheat prices in the medieval England}

As it was noted in Sect. 2, Herschel's observations (1801) were based on the published wheat prices (Smith, 1776), and showed that five prolonged periods of sunspot numbers correlated with costly wheat. This idea was taken up by the English economist William Jevons (1875, 1982). He directed his attention to the wheat prices from 1259 to 1400 and showed that the time intervals between high prices were close to 10-11 yr. The coincidence of these intervals with the period of the eleven year cycle of solar activity led him to suggesting that the solar activity cycle was a "synchronization" factor in the fluctuations of wheat prices. As a next step, he extrapolated his theory to stock markets of the 19th Century in England and was impressed by a close coincidence of five stock exchange panics with five minima in solar spot numbers that preceded these panics. The Rogers (1887) database on wheat prices in medieval England was used by Pustil'nik, Yom Din, and Dorman (2003) to search for possible influences of solar activity and CR intensity variations 

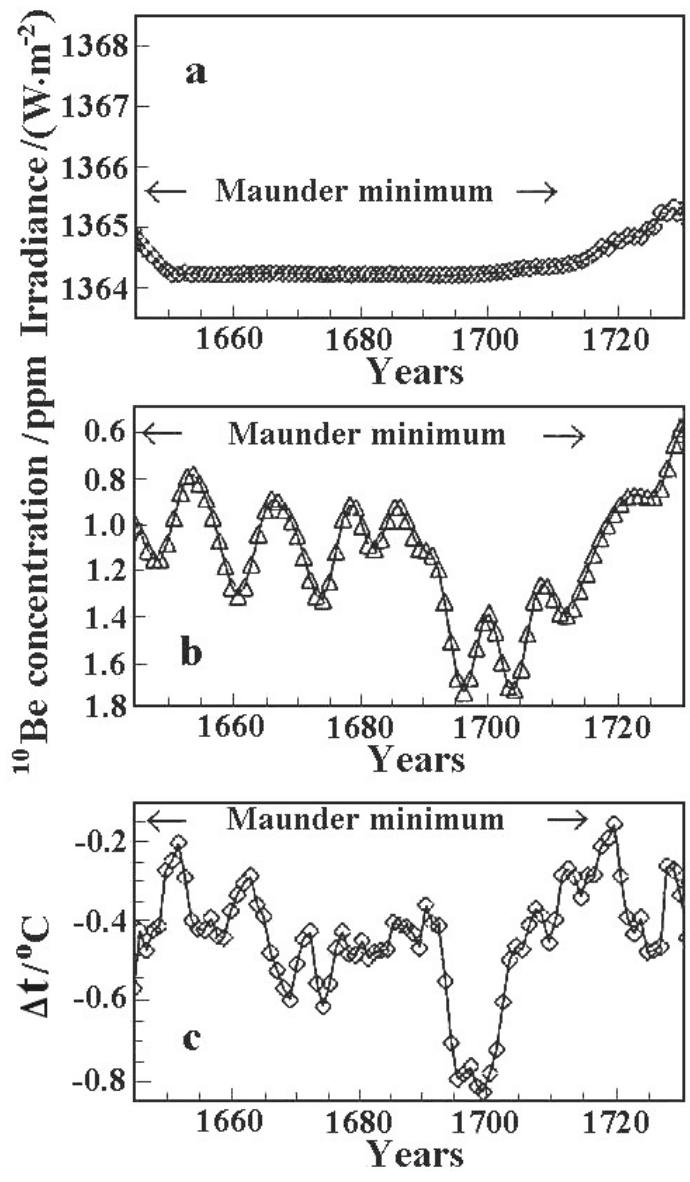

Fig. 5. Situation in the Maunder minimum: (a) - reconstructed solar irradiance (Labitzke and Van Loon, 1993); (b) - CR intensity according to concentration of ${ }^{10} \mathrm{Be}$ (Beer et al., 1991); (c) - reconstructed relative change of air surface temperature, $\Delta t$, for the Northern Hemisphere (Jones et al., 1998). According to Svensmark (2000).

on wheat prices. Obtained results are demonstrated in Figs. 6 and 7.

From Fig. 6 it can be seen that the distributions of intervals between wheat price bursts and between minimums of sunspot numbers (or corresponding maximums of CR intensity) are similar, and from Fig. 7 - that with increases of CR intensity, wheat prices also decreased (let me remind that for the climate in England, with a lot of water, sunny days are most important for wheat production, and these decrease with increases in CR intensity, leading to decreasing of wheat production and increasing of wheat prices). Let me note that in many other regions of our planet, where there is not enough water for agriculture production, the situation expected to be opposite: increasing of CR intensity will lead to increasing of cloudiness, increasing of raining and increasing of wheat and other agriculture production, and to corresponding decreasing of prices.

\section{On the Influence of galactic CR forbush decreases and solar CR increases on rainfall and air temperature}

A decrease of atmospheric ionization leads to a decrease in the concentration of charge condensation centres. In these periods, a decrease of total cloudiness and atmosphere turbulence together with an increase in isobaric levels is observed (Veretenenko and Pudovkin, 1994). As a result, a decrease of rainfall is also expected. Stozhkov et al. (1995a, b, 1996), and Stozhkov (2002) analyzed 70 events of Forbush decreases (defined as a rapid decrease in observed galactic CR intensity, and caused by big geomagnetic storms) observed in 1956-1993 and compared these events with rainfall data over the former USSR. It was found that during the main phase of the Forbush decrease, the daily rainfall levels decreases by about $17 \%$. Similarly, Todd and Kniveton $(2001,2004)$ investigating 32 Forbush decreases over the period 1983-2000, found reduced cloud cover on 12$18 \%$. Laken and Kniveton (2011) investigate 47 Forbush decreases over the period 1985-2006 and confirmed this result of Todd and Kniveton $(2001,2004)$. Artamonova and Veretenenko (2011), using the Apatity neutron monitor data, analyzed daily averaged values of geo-potential heights $(\mathrm{GPH})$ of the main isobaric levels 1000, 850, 700, 500, 300 and $200 \mathrm{mb}$ (NCEP/NCAR data) and found effects of Forbush decreases on the variations of pressure in the lower atmosphere during 48 events in October-March for the period 1980-2006. Mansilla (2011) found that big magnetic storms (produced Forbush decreases) lead to increasing of air temperature and wind's velocity.

During big solar CR events, when CR intensity and ionization in the atmosphere significantly increases, an inverse situation is expected and the increase in cloudiness leads to an increase in rainfall. Studies of Stozhkov et al. (1995a, b, 1996), and Stozhkov (2002) involving 53 events of solar CR enhancements, between 1942-1993, showed a positive increase of about $13 \%$ in the total rainfall over the former USSR.

\section{Convection-diffusion and drift mechanisms for long- term galactic CR variation: possible forecasting of some part of climate change caused by cosmic rays}

From above consideration follows that CR may be considered as sufficient link determined some part of solar wind as element of space weather influence on the climate change. From this point of view it is important to understand mechanisms of galactic CR long-term variations and on this basis to forecast expected CR intensity in near future. In Dorman (2005a, b, 2006) it was made on basis of monthly sunspot numbers $W$ with taking into account time-lag between processes on the Sun and situation in the interplanetary space as well as the sign of general magnetic field (convection diffusion + drift modulations, see Fig. 8). 
Hystogram of Price Bursts Intervals

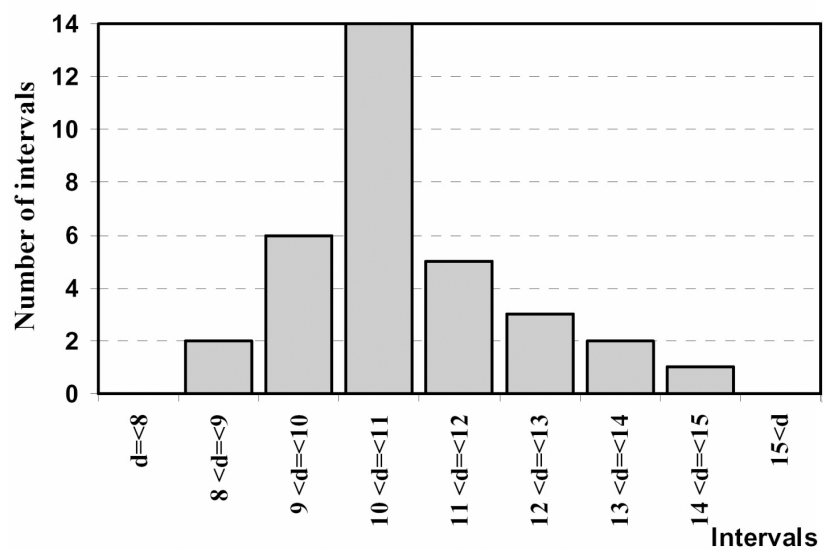

Hystogram of the Sunspot Min-Min intervals

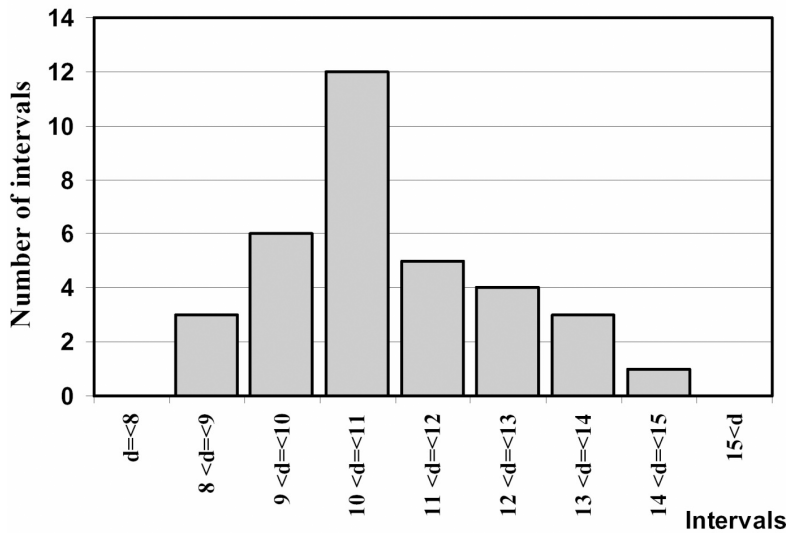

Fig. 6. Distributions of intervals $d$ (in years) between wheat price bursts during 1249-1702 (left), and of intervals between minimums of sunspot numbers during 1700-2000 (right). According to Pustil'nik et al. (2003).

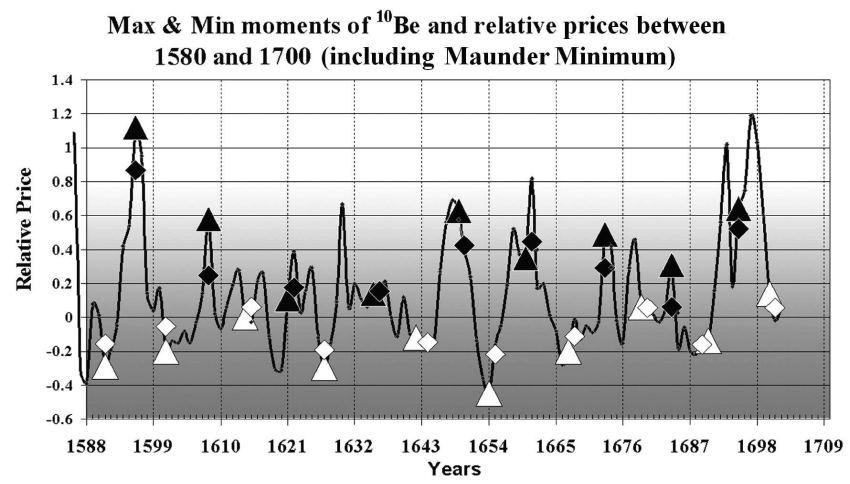

Fig. 7. Relative wheat prices at moments of minimum and maximum CR intensity determined according to ${ }^{10} \mathrm{Be}$ data (Beer et al., 1998). White (black) diamonds show prices averaged for three-year intervals centred at moments of minimum (maximum) CR intensity. White (black) triangles show prices at moments of minimum (maximum) CR intensity. From Pustil'nik et al. (2003).

From obtained results it follows that in the frame of convection-diffusion and drift models can be determined with very good accuracy expected galactic CR intensity in the past (when $W$ are known) as well as behaviour of CR intensity in future (if sunspot numbers $W$ can be well forecast).

\section{Influence of main geomagnetic field on global climate change through $C R$ cutoff rigidity variation}

When we consider galactic CR variations $\Delta I / I_{0}$ as a factor influencing global climate change, we need to take into account not only the effects of the solar wind and Heliosphere, but also cutoff rigidity $R_{\mathrm{C}}$ changes on CR intensity variation: $\Delta I / I_{0}=-\Delta R_{\mathrm{C}} \cdot W\left(R_{\mathrm{C}}, R_{\mathrm{C}}\right)$, where $\Delta R_{\mathrm{C}}$ is the change

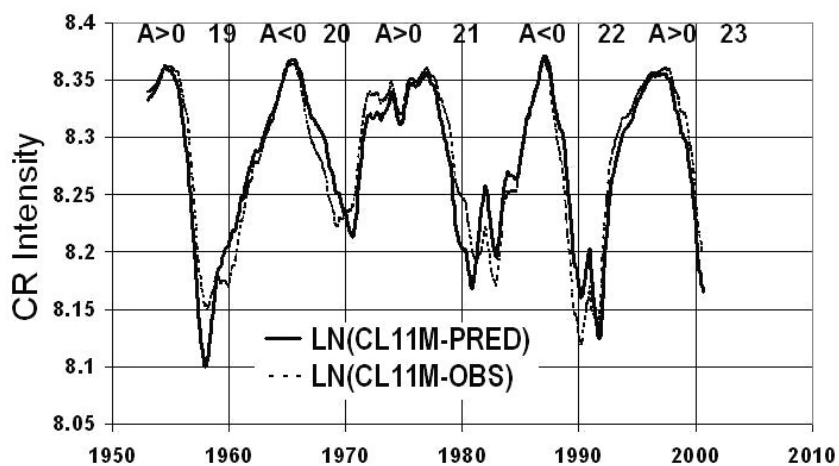

Fig. 8. Comparison of observed galactic $\mathrm{CR}$ variations during about $50 \mathrm{yr}$ (as 11 month moving averaged at Climax NM) - $\ln$ (CL11MOBS) with predicted in the frame of convection-diffusion and drift modulations $\ln$ (CL11M-PRED). According to Dorman (2006).

of cutoff rigidity and $W\left(R_{\mathrm{C}}, R_{\mathrm{C}}\right)$ is the coupling function $W\left(R_{\mathrm{C}}, R\right)$ at $R=R_{\mathrm{C}}$ (see in details in Dorman, 2004). Expected changes of cutoff rigidities were found in many papers (e.g. Bhattacharyya and Mitra, 1997; Shea and Smart, 2003; Kudela and Bobik, 2004; see review in Dorman, 2009). Results of trajectory calculations of $R_{\mathrm{C}}$ changes are shown in Table 2 (from Shea and Smart, 2003). It can be seen a big changes of cutoff rigidities in some places. We suppose to investigate this problem in near future in more details in possible connection with historically known places on the World where local climate changes pressed people to move to other places with better climate. It is not excluded that observed 22-yr hurricane cycle connection with geomagnetic and solar activity cycles (Mendoza and Pazos, 2009) may be caused also by the link of these cycles with cosmic rays and their influence on on meteorological processes. 
Table 2. Vertical cutoff rigidities $R_{\mathrm{C}}$ (in GV) for epochs $1600,1700,1800,1900$, and 2000, as well as change from 1900 to 2000 . According to Shea and Smart (2003).

\begin{tabular}{rrrrrrrrl}
\hline Lat. & Long. & Epoch & Epoch & Epoch & Epoch & Epoch & $\begin{array}{r}\text { Change } \\
1900-2000\end{array}$ & Region \\
& $(\mathrm{E})$ & 2000 & 1900 & 1800 & 1700 & 1600 & \\
\hline 55 & 30 & 2.30 & 2.84 & 2.31 & 1.49 & 1.31 & +0.54 & Europe \\
50 & 0 & 3.36 & 2.94 & 2.01 & 1.33 & 1.81 & +0.42 & Europe \\
50 & 15 & 3.52 & 3.83 & 2.85 & 1.69 & 1.76 & -0.31 & Europe \\
40 & 15 & 7.22 & 7.62 & 5.86 & 3.98 & 3.97 & -0.40 & Europe \\
45 & 285 & 1.45 & 1.20 & 1.52 & 2.36 & 4.1 & +0.25 & N. Amer. \\
40 & 255 & 2.55 & 3.18 & 4.08 & 4.88 & 5.89 & -0.63 & N. Amer. \\
20 & 255 & 8.67 & 12.02 & 14.11 & 15.05 & 16.85 & -3.35 & N. Amer. \\
20 & 300 & 10.01 & 7.36 & 9.24 & 12.31 & 15.41 & +2.65 & N. Amer. \\
50 & 105 & 4.25 & 4.65 & 5.08 & 5.79 & 8.60 & +0.40 & Asia \\
40 & 120 & 9.25 & 9.48 & 10.24 & 11.28 & 13.88 & -0.23 & Asia \\
35 & 135 & 11.79 & 11.68 & 12.40 & 13.13 & 14.39 & +0.11 & Japan \\
-25 & 150 & 8.56 & 9.75 & 10.41 & 11.54 & 11.35 & -1.19 & Australia \\
-35 & 15 & 4.40 & 5.93 & 8.41 & 11.29 & 12.19 & -1.53 & S. Africa \\
-35 & 300 & 8.94 & 12.07 & 13.09 & 10.84 & 8.10 & -3.13 & S. Amer. \\
\hline
\end{tabular}

\section{Solar system moving around the galactic centre and crossing Galaxy's arms: influence on the Earth's climate through $\mathbf{C R}$ and dust}

Above we considered space factors acted on the Earth's Climate mainly through CR in frame of scales not bigger than one thousand years. In Fig. 9 are shown data on planetary surface temperature changing during the last 520 million years, caused to the moving of the Solar system around the centre of our Galaxy and crossing galactic arms with bigger probability to interact with molecular-dust clouds and supernova remnants (with bigger intensity of CR and higher density of space dust, which both lead to increasing of cloudiness and decreasing of planetary surface temperature). From Fig. 9 it can be seen that during the past 520 million years, there were four periods with surface temperatures lower than at present time and four periods with higher temperatures.

\section{Discussion}

Let me note with gratitude to both Referees that this Section was induced by their comments. We considered above the change of planetary climate as caused mostly by two space factors: cosmic rays and space dust. This we advocate with the use of results obtained over long time periods, from about ten thousand years to many millions of years. We also considered very short events of only one or a few days, such as Forbush effects and Ground Level Enhancements (GLE). In these cases, it is necessary to use a superposed method, summing over many events to sufficiently reduce the relative role of meteorological factors, active incident to the aforementioned short events (see Sect. 9).

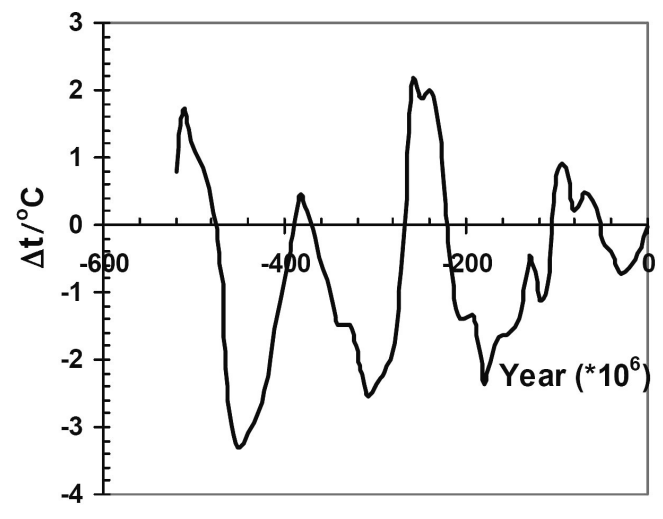

Fig. 9. Changes of planetary air temperature, $\Delta t$, near the Earth's surface for the last 520 million years according to the paleenvironmental records. According to Veizer et al. (2000).

Analysis of Kristjánsson and Kristiansen (2000) contradicts the simple relationship between cloud cover and radiation assumed in the cosmic-ray-cloud-climate hypothesis, because this relationship really is much more complicated and is not the main climate-causal relationship. I agree with this result and with result of Erlykin et al. (2009a, b) and Erlykin and Wolfendale (2011) that there is no simple causal connection between CR and low cloud coverage (LCC), that there is no correlation between CR and LCC for short-term variations, and that while there is correlation between $\mathrm{CR}$ and LCC for long-term variations, that this connection can explain not more than about $20 \%$ of observed climate change. But the supposition of Erlykin et al. (2009a, b) that the observed long-term correlation between cosmic ray intensity and cloudiness may be caused by parallel separate correlations between CR, cloudiness and solar activity contradicts 
the existence of the hysteresis effect in cosmic rays caused by the big dimensions of the Heliosphere (Dorman and Dorman, 1967a, b; Dorman et al., 1997; Dorman, 2005a, b, 2006). This effect, which formed a time-lag of cosmic rays relative to solar activity of more than one year (different in consequent solar cycles and increasing inverse to particle energy), gives the possibility of distinguishing phenomena caused by cosmic rays from phenomena caused directly by solar activity (i.e. activity without time lag) (see Fig. 2). The importance of cosmic ray influence on climate compared with the influence of solar irradiation can be seen clearly during the Maunder minimum (see Fig. 5). Cosmic ray influence on climate over a very long timescale of many hundreds of years can be seen from Fig. 1 (through variation of ${ }^{14} \mathrm{C}$ ).

It is necessary to take into account that the main factors influencing climate are meteorological processes: cyclones and anticyclones; air mass moving in vertical and horizontal directions; precipitation of ice and snow (which changes the planetary radiation balance, see Waliser et al., 2011); and so on. Only after averaging for long periods (from one-ten years up to 100-1000 yr and even million of years) did it become possible to determine much smaller factors that influence the climate, such as cosmic rays, dust, solar irradiation, and so on. For example, Zecca and Chiari (2009) show that the dust from comet 1P/Halley, according to data of about the last $2000 \mathrm{yr}$, produces periodic variations in planetary surface temperature (an average cooling of about $0.08^{\circ} \mathrm{C}$ ) with a period $72 \pm 5$ yr. Cosmic dust of interplanetary and interstellar origin, as well as galactic cosmic rays entering the Earth's atmosphere, have an impact on the Earth's climate (Ermakov et al., 2006, 2007, 2009; Kasatkina et al., 2007a, b). Ermakov et al. $(2006,2009)$ hypothesized that the particles of extraterrestrial origin residing in the atmosphere may serve as condensation nuclei and, thereby, may affect the cloud cover. Kasatkina et al. (2007a, b) conjectured that interstellar dust particles may serve as atmospheric condensation nuclei, change atmospheric transparency and, as a consequence, affect the radiation balance. Ogurtsov and Raspopov (2011) show that the meteoric dust in the Earth's atmosphere is potentially one of the important climate forming agents in two ways: (i) particles of meteoric haze may serve as condensation nuclei in the troposphere and stratosphere; (ii) charged meteor particles residing in the mesosphere may markedly change (by a few percent) the total atmospheric resistance and thereby, affect the global current circuit. Changes in the global electric circuit, in turn, may influence cloud formation processes.

Let me underline that there is also one additional mechanism by which cosmic rays influence lower cloud formation, precipitation, and climate change: the nucleation by cosmic energetic particles of aerosol and dust, and through aerosol and dust-increasing of cloudiness. It was shown by Enghoff et al. (2011) in the frame of the CLOUD experiment at CERN that the irradiation by energetic particles (about $580 \mathrm{MeV}$ ) of the air at normal conditions in the closed chamber led to aerosol nucleation (induced by high energy particles), and simultaneously to an increase in ionization (see also Kirkby et al., 2011).

Let me note that in our paper, we considered cosmic rays and dust aerosols separately, but acting in the same direction. Increasing cosmic ray intensity and increasing of aerosols and dust leads to increasing of cloudiness and a corresponding decrease of planetary surface temperature. Now, consistant with the experimental results of Enghoff et al. (2011) on aerosol nucleation in the frame of the CLOUD Project on the accelerator at CERN (see short description of this Project in Dorman, 2004), it was found that with increasing intensity of energetic particles, the rate of formation of aerosol nucleation in the air at normal conditions increased sufficiently. This result can be considered as some physical evidence of the cosmic ray-cloud connection hypothesis.

\section{Conclusions}

When considering CR variations as one of the possible causes of long-term global climate change, we need to take into account not only CR modulation by the solar wind but also the changing of geomagnetic cutoff rigidities (see Table 2). This is especially important when we consider climate change on a scale of between $10^{3}$ and $10^{6} \mathrm{yr}$. Paleomagnetic investigations show that during the last $3.6 \times 10^{6} \mathrm{yr}$, the magnetic field of the Earth has changed polarity nine times. The Earth's magnetic moment has changed as well, sometimes having a value of only one-fifth of its present value (Cox et al., 1967). This corresponds to a decreasing of the cutoff rigidity, which in turn leads to an increasing of CR intensity and a decreasing of the surface temperature. When we consider the situation in the frame of timescales of many thousands and millions of years, we need to take into account also possible changes of galactic CR intensity out of the Heliosphere. It is furthermore not excluded that the gradual increasing of planetary surface temperature observed in the last hundred years is caused not by anthropogenic factors, but by space factors (mainly by CR intensity variation, see Fig. 4). In my opinion, it is necessary to continue investigations on the connection between CR intensity and climate factors like cloudiness, raining, and surface temperature, not only by statistical investigations in the frame of different timescales, but also by special experiments on accelerators and through the development of physical models. As we mentioned in Sect. 11, it will also be important to investigate the possible connection between big changes in cosmic ray cutoff rigidity and historically known places in the world where local climate change pressed people to move to other places with better climates.

Acknowledgements. My great thanks to Israel Ministry of Science and Tel Aviv University, to Abraham Sternlieb, Uri Dai, Itzik ben Israel, Zvi Kaplan, to Colin Price for constant interest and support of the work of Israel Cosmic Ray and Space Weather Centre and 
Emilio Sègre Observatory, Lev Pustil'nik, W. W. Wolfendale, and Igor Zukerman for fruitful discussions, David Shai Applbaum for help to improve English in this paper, and both Reviewers for important and useful comments.

Guest Editor M. Balikhin thanks two anonymous referees for their help in evaluating this paper.

\section{References}

Artamonova, I. and Veretenenko, S.: Galactic cosmic ray variation influence on baric system dynamics at middle latitudes, J. Atmos. Sol.-Terr. Phy., 73, 366-370, 2011.

Barnard, L., Lockwood, M., Hapgood, M. A., Owens, M. J., Davis, C. J., and Steinhilber, F.: Predicting space climate change, Geophys. Res. Lett., 38, L16103, doi:10.1029/2011GL048489, 2011.

Beer, J., Raisbeck, G. M., and Yiou, F.: Time variations of ${ }^{10} \mathrm{Be}$ and solar activity, in: The Sun in Time, edited by: Sonett, C. P., Giampapa, M. S., and Matthews, M. S., University of Arizona Press, 343-359, 1991.

Beer J., Tobias, S., and Weiss, N.: An active Sun throughout the Maunder minimum, Sol. Phys.., 181, 237-249, 1998.

Belov, A. V., Dorman, L. I., Gushchina, R. T., Obridko, V. N., Shelting, B. D., and Yanke, V. G.: Prediction of expected global climate change by forecasting of galactic cosmic ray intensity time variation in near future based on solar magnetic field data, Adv. Space Res., 35, 491-495, 2005.

Bhattacharyya, A. and Mitra, B.: Changes in cosmic ray cut-off rigidities due to secular variations of the geomagnetic field, Ann. Geophys., 15, 734-739, doi:10.1007/s00585-997-0734-6, 1997.

Cox, A., Dalrymple, G. B., and Doedl, R. R.: Reversals of the Earth's magnetic field, Sci. Am., 216, 44-54, 1967.

Dickinson, R. E.: Solar variability and the lower atmosphere, B. Am. Meteorol. Soc., 56, 1240-1248, 1975.

Dobrica, V., Demetrescu, C., Boroneant, C., and Maris, G.: Solar and geomagnetic activity effects on climate at regional and global scales: Case study-Romania, J. Atmos. Sol.-Terr. Phy., 71, 17271735, 2009.

Dorman, L. I.: Cosmic Rays in the Earth's Atmosphere and Underground, Kluwer Academic Publishers, Dordrecht/Boston/London, 2004.

Dorman, L. I.: Prediction of galactic cosmic ray intensity variation for a few (up to 10-12) years ahead on the basis of convection-diffusion and drift model, Ann. Geophys., 23, 30033007, doi:10.5194/angeo-23-3003-2005, 2005a.

Dorman, L. I.: Estimation of long-term cosmic ray intensity variation in near future and prediction of their contribution in expected global climate change, Adv. Space Res., 35, 496-503, 2005 b.

Dorman, L. I.: Long-term cosmic ray intensity variation and part of global climate change, controlled by solar activity through cosmic rays, Adv. Space Res., 37, 1621-1628, 2006.

Dorman, L. I.: Natural hazards for the Earth's civilization from space, 1. Cosmic ray influence on atmospheric processes, Proc. of 2-nd Humboldt Symposium, Lima, 2007.

Dorman, L. I.: Cosmic Rays in Magnetospheres of the Earth and other Planets, Springer, Netherlands, 2009.

Dorman, L. I. and Dorman, I. V.: Possible influence of cosmic rays on climate through thunderstorm clouds, Adv. Space Res., 35, 476-483, 2005.
Dorman, L. I., Libin, I. Ya., Mikalayunas, M. M., and Yudakhin, K. F.: On the connection between cosmophysical and geophysical parameters in 19-20 cycles of solar activity, Geomagn. Aeronomy, 27, 303-305, 1987.

Dorman, L. I., Libin, I. Ya., and Mikalajunas, M. M.: About the possibility of the influence of cosmic factors on weather, spectral analysis: cosmic factors and intensity of storms, The Regional Hidrometeorology (Vilnius), 12, 119-134, 1988a.

Dorman, L. I., Libin, I. Ya., and Mikalajunas, M. M.: About the possible influence of the cosmic factors on the weather. Solar activity and sea storms: instantaneous power spectra, The Regional Hidrometeorology (Vilnius), 12, 135-143, 1988b.

Dorman, L. I., Villoresi, G., Dorman, I. V., Iucci, N., and Parisi, M.: On the expected CR intensity global modulation in the Heliosphere in the last several hundred years, Proc. 25-th Intern. Cosmic Ray Conference, Durban (South Africa), 7, 345-348, 1997.

Dorman, L. I., Dorman, I. V., Iucci, N., Parisi, M., Ne'eman, Y., Pustil'nik, L. A., Signoretti, F., Sternlieb, A., Villoresi, G., and Zukerman, I. G.: Thunderstorms Atmospheric Electric Field Effect in the Intensity of Cosmic Ray Muons and in Neutron Monitor Data, J. Geophys. Res., 108, 1181, doi:10.1029/2002JA009533, 2003.

Dorman, I. V. and Dorman, L. I.: Solar wind properties obtained from the study of the 11-year cosmic ray cycle. 1, J. Geophys. Res., 72, 1513-1520, 1967a.

Dorman, I. V. and Dorman, L. I.: Propagation of energetic particles through interplanetary space according to the data of 11-year cosmic ray variations, J. Atmos. Terr. Phys., 29, 429-449, 1967b.

Enghoff, M. B., Pedersen, J. O. P., Uggerhøj, U. I., Paling, S. M., and Svensmark, H.: Aerosol nucleation induced by a high energy particle beam, Geophys. Res. Lett., 38, L09805, doi:10.1029/2011GL047036, 2011.

Erlykin, A. D. and Wolfendale, A. W.: Cosmic ray effects on cloud cover and the irrelevance to climate change, J. Atmos. Sol.-Terr. Phy., 73, 1681-1686, 2011.

Erlykin, A. D., Gyalai, G., Kudela, K., Sloan, T., and Wolfendale, A. W.: Some aspects of ionization and the cloud cover, cosmic ray correlation problem, J. Atmos. Sol.-Terr. Phy., 71, 823-829, 2009a.

Erlykin, A. D., Gyalai, G., Kudela, K., Sloan, T., and Wolfendale, A. W.: On the correlation between cosmic ray intensity and cloud cover, J. Atmos. Sol.-Terr. Phy., 71, 1794-1806, 2009 b.

Ermakov, V. I., Okhlopkov, V. P., and Stozhkov, Yu. I.: Effect of cosmic dust on terrestrial climate, Kratk. Soob'sh. Fiz. FIAN, 3, 41-51, 2006 (in Russian).

Ermakov, V. I., Okhlopkov, V. P., and Stozhkov, Yu. I.: Effect of cosmic dust on cloudiness, albedo, and terrestrial climate, Vestn. Mosk. Univ., Ser. 3: Fiz. Astron., 5, 41-45, 2007 (in Russian).

Ermakov, V. I., Okhlopkov, V. P., and Stozhkov, Yu. I.: Cosmic rays and dust in the Earth's atmosphere, Izv. Ross. Akad. Nauk, Ser. Fiz., 73, 434-436, 2009 (in Russian).

Friis-Christensen, E. and Lassen, K.: Length of the solar cycle: an indicator of solar activity closely associated with climate, Science, 254, 698-700, 1991.

Haigh, J. D.: The impact of solar variability on climate, Science, 272, 981-984, 1996.

Hartmann, D. L.: Radiative effects of clouds on the Earth's climate, in: Aerosol-Cloud-Climate Interactions, Intern. Geophys. Ser., 
54, edited by: Hobbs, P. V., Academic Press Inc., San Diego, CA, 151-173, 1993.

Herschel, W.: Observations tending to investigate the Nature of the Sun, in order to find the Causes or Symptoms of its variable Emission of Light and Heat; with Remarks on the Use that may possibly be drawn from Solar Observations, Philos. T. R. Soc. Lond., 91, Part 1, 265-318, 1801.

Hong, P. K., Miyahara, H., Yokoyama, Y., Takahashi, Y., and Sato, M.: Implications for the low latitude cloud formations from solar activity and the quasi-biennial oscillation, J. Atmos. Sol.-Terr. Phy., 73, 587-591, 2011.

Jevons, W. S.: Commercial crises and sun-spots, Nature, 19, 33-37, 1875.

Jevons, W. S.: The solar commercial cycle, Nature, 26, 226-228, 1882.

Jones, P. D., Briffa, K. R., Barnett, T. P., and Tett, S. F. B.: High resolution palaeoclimatic records for the last millennium: interpretation, integration and comparison with general circulation model control run temperatures, The Holocene, 8, 455-471, 1998.

Kasatkina, E. A., Shumilov, O. I., and Krapiec, M.: On periodicities in long term climatic variations near $68^{\circ} \mathrm{N}, 30^{\circ} \mathrm{E}$, Adv. Geosci., 13, 25-29, 2007a.

Kasatkina, E. A., Shumilov, O. I., Lukina, N. V., Krapiec, M., and Jacoby, G.: Stardust component in tree rings, Dendrochronologia, 24, 131-135, 2007b.

Kirkby, J., Curtius, J., Almeida, J., Dunne, E., Duplissy, J., Ehrhart, S., Franchin, A., Gagné, S., Ickes, L., Kürten, A., Kupc, A., Metzger, A., Riccobono, F., Rondo, L., Schobesberger, S., Tsagkogeorgas, G., Wimmer, D., Amorim, A., Bianchi, F., Breitenlechner, M., David, A., Dommen, J., Downard, A., Ehn, M., Flagan, R. C., Haider, S., Hanse, A., Hauser, D., Jud, W., Junninen, H., Kreiss, F., Kvashin, A., Laaksonen, A., Lehtipalo, K., Lima, J., Lovejoy, E. R., Makhmutov, V., Mathot, S., Mikkilä, J., Minginette, P., Mogo, S., Nieminen, T., Onnela, A., Pereira, P., Petäjä, T., Schnitzhofer, R., Seinfeld, J. H., Sipilä, M., Stozhkov, Y., Stratmann, F., Tomé, A., Vanhanen, J., Viisanen, Y., Vrtala, A., Wagner, P. E., Walther, H., Weingartner, E., Wex, H., Winkler, P. M., Carslaw, K. S., Worsnop, D. R., Baltensperger, U., and Kulmala, M.: Role of sulphuric acid, ammonia and galactic cosmic rays in atmospheric aerosol nucleation, Letter, 476, 429-433, doi:10.1038/nature10343, 2011.

Kudela, K. and Bobik, P.: Long-term variations of geomagnetic rigidity cutoffs, Sol. Phys., 224, 423-431, 2004.

Labitzke, K. and van Loon, H: Some recent studies of probable connections between solar and atmospheric variability, Ann. Geophys., 11, 1084-1094, 1993.

Laken, B. A. and Kniveton, D. R.: Forbush decreases and Antarctic cloud anomalies in the upper troposphere, J. Atmos. Sol.-Terr. Phy., 73, 371-376, 2011.

Lassen, K. and Friis-Christensen, E.: Variability of the solar cycle length during the past five centuries and the apparent association with terrestrial climate, J. Atmos. Sol.-Terr. Phy., 57, 835-845, 1995.

Lean, J., Beer, J., and Breadley, R.: Reconstruction of solar irradiance since 1610: implications for climate change, Geophys. Res. Lett., 22, 3195-3198, 1995.

Mansilla, G. A.: Response of the lower atmosphere to intense geomagnetic storms, Adv. Space Res., 48, 806-810, 2011.
Markson, R.: Solar modulation of atmospheric electrification and possible implications for the Sun-weather relationship, Nature, 273, 103-109, 1978.

Marsh, N. and Svensmark, H.: Low cloud properties influenced by cosmic rays, Phys. Rev. Lett., 85, 5004-5007, 2000a.

Marsh, N. and Svensmark, H.: Cosmic rays, clouds, and climate, Space Sci. Rev., 94, 215-230, 2000 b.

Mendoza, B. and Pazos, M.: A 22 yr hurricane cycle and its relation with geomagnetic activity, J. Atmos. Sol.-Terr. Phy., 71, 20472054, 2009.

Ney, E. R.: Cosmic radiation and weather, Nature, 183, 451-452, 1959.

Ogurtsov, M. G. and Raspopov, O. M.: Possible impact of interplanetary and interstellar dust fluxes on the Earth's climate, Geomagn. Aeronomy, 51, 275-283, 2011.

Price, C.: Evidence for a link between global lightning activity and upper tropospheric water vapour, Nature, 406, 290-293, 2000.

Pudovkin, M. and Veretenenko, S.: Cloudiness decreases associated with Forbush-decreases of galactic cosmic rays, J. Atmos. Sol.Terr. Phy., 57, 1349-1355, 1995.

Pudovkin, M. and Veretenenko, S.: Variations of the cosmic rays as one of the possible links between the solar activity and the lower atmosphere, Adv. Space Res., 17, 161-164, 1996.

Pudovkin, M. I. and Raspopov, O. M.: The mechanism of action of solar activity on the state of the lower atmosphere and meteorological parameters (a review), Geomagn. Aeronomy, 32, 593 608, 1992.

Pustil'nik, L., Yom Din, G., and Dorman, L.: Manifestations of Influence of Solar Activity and Cosmic Ray Intensity on the Wheat Price in the Medieval England (1259-1703 Years), Proc. 28th Intern. Cosmic Ray Conf., Tsukuba, 7, 4131-4134, 2003.

Rogers, J. E. T.: Agriculture and Prices in England, Vol. 1-8, Oxford, Clarendon Press, 1887.

Schlegel, K., Diendorfer, G., Them, S., and Schmidt, M.: Thunderstorms, lightning and solar activity - Middle Europe, J. Atmos. Sol.-Terr. Phy., 63, 1705-1713, 2001.

Shapiro, A. I., Schmutz, W., Rozanov, E., Schoell, M., Haberreiter, M., Shapiro, A. V., and Nyeki, S.: A new approach to the long-term reconstruction of the solar irradiance leads to large historical solar forcing, Astron. Astrophys., 529, A67, doi:10.1051/0004-6361/201016173, 2011.

Shea, M. A. and Smart, D. F.: Preliminary Study of the 400-Year Geomagnetic Cutoff Rigidity Changes, Cosmic Rays and Possible Climate Changes, Proc. 28th Intern. Cosmic Ray Conf., Tsukuba, 7, 4205-4208, 2003.

Shindell, D., Rind, D., Balabhandran, N., Lean, J., and Lonengran, P.: Solar cycle variability, ozone, and climate, Science, 284, 305308, 1999.

Smith, A.: An Inquiry into the Nature and Causes of the Wealth of Nations, W. Strahan \& T. Cadell, London, 1776.

Smith, G. L., Priestley, K. J., Loeb, N. G., Wielicki, B. A., Charlock, T. P., Minnis, P., Doelling, D. R., and Rutan, D. A.: Clouds and Earth Radiant Energy System (CERES), a review: Past, present and future, Adv. Space Res., 48, 254-263, 2011.

Stozhkov, Yu. I.: The role of cosmic rays in atmospheric processes, J. Phys. G Nucl. Partic., 28, 1-11, 2002.

Stozhkov, Yu. I., Zullo Jr., J., Martin, I. M., Pellegrino, G. Q., Pinto, H. S., Bazilevskaya, G. A., Bezerra, P. C., Makhmutov, V. S., Svirzevsky, N. S., and Turtelli Jr., A.: Rainfalls during great 
Forbush-decreases, IL Nuovo Cimento C, C18, 335-341, 1995a. Stozhkov, Yu. I., Pokrevsky, P. E., Martin, I. M., Zullo Jr., J., Pellegrino, G. Q., Pinto, H. S., and Turtelli Jr., A.: Cosmic Ray Fluxes in Atmosphere and Precipitations, Proc. 24th Intern. Cosmic Ray Conf., Rome, Italy, 4, 1122-1125, 1995b.

Stozhkov, Yu. I., Pokrevsky, P. E., Zullo Jr., J., Martin, I. M., Okhlopkov, V. P., Pellegrino, Z. K., Pinto, K. S., Bezerra, P. S., and Turtelli, A.: Effect of charged particle flows on the intensity of precipitations, Geomagn. Aeron. (Russia), 36, 211-216, 1996 (in Russian).

Svensmark, H.: Cosmic rays and Earth's climate, Space Sci. Rev., 93, 175-185, 2000.

Tinsley, B. A.: Influence of solar wind on the global electric circuit, and inferred effects on cloud microphysics, temperature, and dynamics in the troposphere, Space Sci. Rev., 94, 231-258, 2000.

Todd, M. C. and Kniveton, D. R.: Changes in cloud cover associated with Forbush decreases of galactic cosmic rays, J. Geophys. Res., 106, 32031-32042, 2001.
Todd, M. C. and Kniveton, D. R.: Short-term variability in satellitederived cloud cover and galactic cosmic rays: an update, J. Atmos. Sol.-Terr. Phy., 66, 1205-1211, 2004.

Veizer, J., Godderis, Y., and Francois, I. M.: Evidence for decoupling of atmospheric $\mathrm{CO}_{2}$ and global climate during the Phanerozoiceon, Nature, 408, 698-701, 2000.

Veretenenko, S. V. and Pudovkin, M. I.: Effects of Forbushdecreases in cloudiness variations, Geomagn. Aeronomy, 34, 3844, 1994.

Waliser, D. E., Li, J.-L. F., L'Ecuyer, T. S., and Chen, W.-T.: The impact of precipitating ice and snow on the radiation balance in global climate models, Geophys. Res. Lett., 38, L06802, doi:10.1029/2010GL046478, 2011.

Zecca, A. and Chiari, L.: Comets and climate, J. Atmos. Sol.-Terr. Phy., 71, 1766-1770, 2009. 